\title{
openheart Renin-angiotensin system inhibitors in patients with or without ischaemic mitral regurgitation after acute myocardial infarction
}

Kitae Kim, Shuichiro Kaji, Manabu Kasamoto, Ryosuke Murai, Yasuhiro Sasaki, Takeshi Kitai, Takafumi Yamane, Natsuhiko Ehara, Atsushi Kobori, Makoto Kinoshita, Yutaka Furukawa

To cite: Kim K, Kaji S, Kasamoto M, et al. Reninangiotensin system inhibitors in patients with or without ischaemic mitral regurgitation after acute myocardial infarction. Open Heart 2017;4:e000637. doi:10.1136/ openhrt-2017-000637

Received 1 April 2017 Revised 7 October 2017 Accepted 7 November 2017

Department of Cardiovascular Medicine, Kobe City Medical Center General Hospital, Kobe, Japan

Correspondence to Dr Shuichiro Kaji; skaji@theia. ocn.ne.jp

\section{ABSTRACT}

Objective Little is known about the long-term effects of renin-angiotensin system inhibitors (RASI) on cardiovascular events in patients after acute myocardial infarction (AMI) with ischaemic mitral regurgitation (IMR). The purpose of this study was to investigate the association of RASI with the incidence of adverse cardiac events in patients with or without IMR after AMI. Methods We reviewed charts of 1208 consecutive patients admitted with AMI who underwent emergency coronary angiography between 2000 and 2012. After excluding patients who died within 30 days, 551 patients were diagnosed to have mild or greater MR by transthoracic echocardiography (patients with IMR); the remaining 505 patients had no or trivial MR (non-IMR patients).

Results Of the study patients, 395 (72\%) patients with IMR and $403(80 \%)$ non-IMR patients received RASI. Survival analysis showed that freedom from cardiac death and the composite of cardiac death and heart failure (HF) was significantly higher in patients with IMR receiving RASI than in those not receiving $\mathrm{RASI}(\mathrm{P}<0.001$ and $\mathrm{P}<0.001$, respectively). Moreover, adjusted survival analysis using the inverse probability treatment weighting method showed a significant association of RASI therapy with reduced cardiac death $(\mathrm{P}=0.010)$ and the composite of cardiac death and HF $(P=0.044)$ in patients with IMR. However, in non-IMR patients, there were no significant associations between RASI therapy and the outcome measures.

Conclusions RASI therapy was associated with a lower incidence of adverse cardiac events in patients with IMR after AMI, but not in patients without IMR.

\section{INTRODUCTION}

Mitral regurgitation (MR) complicates the course of acute myocardial infarctions (AMI) in $13 \%$ to $50 \%$ of patients. ${ }^{12}$ Postinfarction ischaemic MR (IMR) portends a poor prognosis during long-term follow-up and has been identified as an independent predictor of heart failure (HF) and reduced long-term survival. ${ }^{3-6}$ It has been recognised that vasodilator therapy such as nitroprusside could

\section{KEY QUESTIONS}

What is already known about this subject? Renin-angiotensin system inhibitors (RASI) are useful in reducing mortality in patients with left ventricular dysfunction after acute myocardial infarction (AMI).

What does this study add?

Little is known about the long-term effect of RASI in patients with or without ischaemic mitral regurgitation (IMR) after AMI. This study investigated the effect of RASI with the long-term outcomes in patients with or without IMR after AMI in the reperfusion setting.

How might this impact on clinical practice? Our results suggest that patients with IMR might receive clinical benefit from RASI therapy after AMI regardless of MR severity and left ventricular dysfunction. Introduction at a low dose and uptitration of RASI should always be considered even in patients with IMR who seem to be intolerant to RASI therapy.

improve the severity of IMR by decreasing left ventricular (LV) after load afterload and increasing forward stroke volume. ${ }^{78}$

Previous studies have shown that ACE inhibitors (ACEIs) may improve MR severity in patients with IMR. ${ }^{910}$ In addition, a study in animal model demonstrated that longterm ACEI therapy prevented the worsening of IMR by inhibiting progression of LV dilatation. ${ }^{11}$ The favourable effects of ACEIs on mortality of patients with LV dysfunction after AMI are well established by previous large-scale randomised controlled trials. ${ }^{12-14}$ Also, angiotensin-receptor blockers (ARBs) were shown to be non-inferior to ACEIs in patients with previous MI or HF. ${ }^{15-17}$ However, the clinical outcome in the presence or absence of IMR has not been previously reported. Although guideline-directed medical therapy for $\mathrm{HF}$ including $\beta$-blockers and ACEIs/ARBs is 
recommended for all patients with $\mathrm{LV}$ dysfunction and IMR, ${ }^{18}$ little is known about the long-term effect of medical therapy in patients with IMR. Moreover, there is controversy whether ACEI improves clinical outcomes in patients with preserved LV ejection fraction (EF) after AMI, ${ }^{19}$ stable coronary artery disease. ${ }^{20}$ The purpose of this study was to investigate the association of rennin-angiotensin system inhibitor (RASI) with the long-term outcomes in patients with or without IMR after AMI in the reperfusion setting.

\section{METHODS}

\section{Patient characteristics}

Between January 2000 and December 2012, 1208 consecutive patients were admitted to our hospital for AMI and underwent emergency coronary angiography. Patients who died within 30 days $(n=66)$ and those who did not undergo transthoracic echocardiography during index hospitalisation $(n=85)$ were excluded from the study. Thus, 551 patients diagnosed to have mild or greater MR (patients with IMR) and 505 patients diagnosed to have no or trivial MR (non-IMR patients) by transthoracic echocardiography were analysed. No patient had significant mitral valve prolapse as a cause of MR. A diagnosis of AMI was made if the patient fulfilled at least two of the following three criteria: (1) history of central chest pressure, pain or tightness lasting $30 \mathrm{~min}$; (2) typical ECG changes (ST segment elevation $\geq 0.1 \mathrm{mV}$ in $\geq 1$ standard limb lead or $\geq 2$ precordial leads, ST segment depression $\geq 0.1 \mathrm{mV}$ in $\geq 2$ leads, abnormal $\mathrm{Q}$ waves or T-wave inversion in two leads); and (3) an increase in serum creatine kinase (CK) levels of twice the upper normal limit. A total of 936 patients underwent primary percutaneous coronary intervention (PCI), and the remaining 120 patients were treated with coronary artery bypass grafting (CABG; $\mathrm{n}=53$ ) or standard medical therapy including thrombolytic and antiplatelet/anticoagulant therapy ( $\mathrm{n}=67)$.

Baseline characteristics were assessed retrospectively from the medical records. Hypertension was defined as systolic blood pressure (BP) $\geq 140 \mathrm{~mm} \mathrm{Hg}$ or diastolic BP $\geq 90 \mathrm{~mm} \mathrm{Hg}$, or both. Diabetes mellitus was defined as a fasting glucose level $\geq 126 \mathrm{mg} / \mathrm{dL}$, a non-fasting glucose level $\geq 200 \mathrm{mg} / \mathrm{dL}$, an HbA1c level $\geq 6.5 \%$ and/or a previous medical diagnosis of diabetes. Dyslipidaemia was defined as low-density lipoprotein (LDL) cholesterol level $\geq 140 \mathrm{mg} / \mathrm{dL}$, high-density lipoprotein (HDL) cholesterol level $<40 \mathrm{mg} / \mathrm{dL}$ and/or a triglycerides level $\geq 150 \mathrm{mg}$ / dL. Patients with hypoalbuminaemia $(<35 \mathrm{~g} / \mathrm{L})$ and low body mass index $(\mathrm{BMI}<18.5)$ was defined as frail. ${ }^{21}{ }^{22}$ Estimated glomerular filtration rate was assessed as previously reported. ${ }^{23}$

This study was approved by the Institutional Review Board of Kobe City Medical Center General Hospital. Waiver of informed consent was obtained given the nature of the study.

\section{Echocardiographic evaluation}

All patients who underwent echocardiography during index hospitalisation were identified, and the results of all echocardiogram were reviewed by the principal investigator without knowledge of the patients' outcomes and histories. When echocardiography demonstrated that the main cause of MR was leaflet tethering by displacement of papillary muscles as a consequence of regional or global LV dysfunction (not the pathology of mitral valve apparatus including leaflets and chordae tendineae), we defined MR as IM. If patients had both leaflet tethering and degenerative changes such as leaflet thickening or mitral annular calcification, we classified these patients as having IMR. The severity of MR was evaluated semiquantitatively from the area of the regurgitant jet by colour Doppler as previously reported. ${ }^{4}$ MR was classified as absent or trivial, mild, and moderate or severe. EF was calculated by the biplane Simpson method. Diastolic function was evaluated by the deceleration time of the early mitral inflow.

\section{Clinical follow-up}

Cardiac death and the composite of cardiac death and HF were analysed. All patients were followed at the outpatient clinic every 4 to 8 weeks after discharge. Further follow-up was done by the referring physician. The longterm follow-up was performed by chart review and telephone contact. Of the 1056 patients, 538 underwent complete follow-up at 5 years. The median follow-up duration was 5.1 years (IQR 2.4-7.2 years). Cardiac death was defined as death related to AMI, arrhythmia, cardiogenic shock, end-stage HF or sudden death. HF was defined as new or worsening symptoms of dyspnoea and fatigue with the presence of pulmonary congestion or peripheral oedema which required hospitalisation. We reviewed all available data to ascertain the immediate cause of death. Only incident episodes of HF after the index MI were considered in the analysis of the association between MR and $\mathrm{HF}$ after MI.

\section{Statistical analysis}

Categorical variables are presented as number and percentage and compared by the $\chi^{2}$ test or Fisher's exact test as appropriate. Continuous variables are presented as mean $\pm \mathrm{SD}$ and were compared by unpaired t tests. Survival analysis was performed by Kaplan-Meier analysis, and differences in survival between groups was examined with the log-rank test. Survival rates are expressed as percentage with mean $\pm \mathrm{SE}$. Cox proportional hazards models were constructed to evaluate the risk of cardiac death or HF according to the presence or absence of RASI therapy. Variables included in the proportional hazards models were chosen from those known to be of clinical interest in post-MI risk stratification, with the goal of keeping the models as parsimonious as possible. Inverse probability of treatment weighted (IPTW) methods based on the propensity score was used to adjust for baseline differences between the IMR patients with 
and without RASI therapy. The included covariates were age, sex, coronary risk factors (hypertension, diabetes mellitus, dyslipidaemia and smoking), frailty, BMI (for non-IMR patients), history of prior MI, Killip classification, moderate or severe MR, anterior MI, revascularisation procedure (PCI or CABG), peak CK level, serum creatinine, $\beta$-blocker therapy and receiving statins. Data analyses were performed with SPSS software (V.22; SPSS) and $\mathrm{R}$ software (V.3.1.1).

\section{RESULTS \\ Patient characteristics and echocardiographic results in patients with IMR}

A total of 551 patients were diagnosed as having mild or greater MR. Among these patients, 23 had both leaflet tethering and degenerative changes. There were no patients with mitral valve prolapse resulting from severe myxomatous degeneration with a redundancy of leaflets known as Barlow's valve or chordal rupture. The median time interval between the index MI and the echocardiogram was 11 days. Of the 551 patients, 395 (72\%) patients received RASI before hospital discharge. None of the patients were deprived of RASI therapy because of low $\mathrm{BP}$ (systolic $\mathrm{BP}<80 \mathrm{~mm} \mathrm{Hg}$ ). Baseline characteristics and echocardiographic results of the patients with and without RASI therapy are shown in table 1 and table 2, respectively. Patients without RASI therapy were older and more likely to have smaller body mass index, higher creatinine level, ST segment elevation MI, higher Killip classification on admission, CABG, moderate or severe MR, and less likely to be taking $\beta$-blockers or statins, compared with patients with RASI therapy. Prevalence of prior MI, peak CK level, LV end-diastolic volume and end-systolic volume were comparable between the two groups.

\section{Survival analysis in patients with IMR}

During the follow-up periods, 73 deaths occurred in patients with IMR. Of these, 31 were cardiac deaths (21 HFs, 7 sudden deaths, 2 MIs, 1 ventricular arrhythmia).

\begin{tabular}{|c|c|c|c|c|}
\hline \multirow[t]{2}{*}{ Characteristics } & \multicolumn{3}{|c|}{ Unadjusted data } & \multirow{2}{*}{$\begin{array}{l}\text { IPTW } \\
\text { P value }\end{array}$} \\
\hline & $\begin{array}{l}\text { RASI (+) } \\
(n=395)\end{array}$ & $\begin{array}{l}\text { RASI (-) } \\
(n=156)\end{array}$ & $P$ value & \\
\hline Age, years, mean $\pm S D$ & $67 \pm 11$ & $71 \pm 10$ & $<0.001$ & 0.15 \\
\hline Gender, male/female & $301 / 94$ & $121 / 35$ & 0.73 & 0.47 \\
\hline \multicolumn{5}{|l|}{ Cardiovascular risk factors } \\
\hline Hypertension, n (\%) & 207 (52) & $82(53)$ & 0.97 & 0.65 \\
\hline Diabetes mellitus, $n(\%)$ & $130(33)$ & $49(31)$ & 0.73 & 0.52 \\
\hline Dyslipidaemia, n (\%) & $157(40)$ & $54(35)$ & 0.26 & 0.70 \\
\hline Current smoker, n (\%) & $129(33)$ & $41(26)$ & 0.14 & 0.84 \\
\hline Frailty & $9(2)$ & 963) & 0.04 & 0.71 \\
\hline $\mathrm{BMI}, \mathrm{kg} / \mathrm{m}^{2}$, mean $\pm \mathrm{SD}$ & $23.7 \pm 3.2$ & $22.9 \pm 3.3$ & 0.01 & 0.50 \\
\hline ST segment elevation MI, n (\%) & $333(84)$ & $117(75)$ & 0.01 & 0.46 \\
\hline Killip classification, n (\%) & $1.2 \pm 0.6$ & $1.5 \pm 1.0$ & $<0.001$ & 0.85 \\
\hline Prior Ml, n (\%) & $32(8)$ & $12(8)$ & 0.87 & 0.57 \\
\hline Primary PCl, n (\%) & $366(93)$ & $123(79)$ & $<0.001$ & 0.24 \\
\hline CABG, n (\%) & $8(2)$ & $24(15)$ & $<0.001$ & 0.79 \\
\hline Peak CK, IU/L & $3119 \pm 2727$ & $3037 \pm 3967$ & 0.78 & 0.73 \\
\hline Serum creatinine, $\mathrm{mg} / \mathrm{dL}$ & $1.07 \pm 0.83$ & $1.66 \pm 1.65$ & $<0.001$ & 0.06 \\
\hline $\mathrm{eGFR}, \mathrm{mL} / \mathrm{min} / 1.73 \mathrm{~m}^{2}$ & $52 \pm 20$ & $40 \pm 22$ & $<0.001$ & 0.08 \\
\hline $\begin{array}{l}\text { ACEI, n (\%) } \\
\text { ARB, n (\%) }\end{array}$ & $\begin{array}{l}288(73) \\
109(27)\end{array}$ & $\begin{array}{l}0(0) \\
0(0)\end{array}$ & $\begin{array}{l}<0.001 \\
<0.001\end{array}$ & $\begin{array}{l}<0.001 \\
<0.001\end{array}$ \\
\hline$\beta$-blocker, $n(\%)$ & $324(82)$ & $101(65)$ & $<0.001$ & 0.61 \\
\hline Statins, n (\%) & $282(71)$ & $85(54)$ & $<0.001$ & 0.73 \\
\hline Initial TIMI grade flow 3, n(\%) & $61(15)$ & $23(15)$ & 0.84 & 0.05 \\
\hline Anterior MI, n (\%) & 155 (39) & $66(42)$ & 0.51 & 0.35 \\
\hline
\end{tabular}

ACEI, ACE inhibitor; ARB, angiotensin receptor blocker; BMI, body mass index; CABG, coronary artery bypass grafting; CK, creatine kinase; eGFR, estimated glomerular filtration rate; IMR, ischaemic mitral regurgitation; IPTW, inverse probability of treatment weighted; MI, myocardial infarction; PCI, percutaneous coronary intervention; RASI, renin-angiotensin system inhibitor; TIMI, Thrombolysis In Myocardial Infarction. 


\begin{tabular}{llll}
\hline $\begin{array}{l}\text { Table } 2 \\
\text { with IMR }\end{array}$ & Baseline echocardiographic findings in patients \\
\hline & $\begin{array}{l}\text { RASI (+) } \\
\text { (n=395) }\end{array}$ & $\begin{array}{l}\text { RASI (-) } \\
\text { (n=156) }\end{array}$ & P value \\
\hline LV EDV, mL & $89 \pm 28$ & $86 \pm 33$ & 0.24 \\
\hline LV ESV, mL & $45 \pm 20$ & $46 \pm 27$ & 0.66 \\
\hline LVEF, \% & $51 \pm 10$ & $49 \pm 12$ & 0.03 \\
\hline LA dimension, cm & $3.7 \pm 0.6$ & $3.7 \pm 0.6$ & 0.40 \\
\hline Moderate/severe MR, $\mathrm{n}(\%)$ & $57(14)$ & $52(33)$ & $<0.001$ \\
\hline Mitral deceleration time, ms & $205 \pm 59$ & $206 \pm 63$ & 0.86 \\
\hline E/A ratio & $1.03 \pm 0.53$ & $1.01 \pm 0.61$ & 0.70 \\
\hline
\end{tabular}

$E D V$, end-diastolic volume; EF, ejection fraction; ESV, end-systolic volume; IMR, ischaemic mitral regurgitation; LA dimension, left atrial dimension; LV, left ventricular; MR, mitral regurgitation; RASI, renin-angiotensin system inhibitor.

Details of the remaining 42 non-cardiac deaths were as follows: cancer $(\mathrm{n}=17)$, infectious disease $(\mathrm{n}=10)$, stroke $(n=4)$, renal failure $(n=1)$, respiratory failure $(\mathrm{n}=1)$, pancreatitis $(\mathrm{n}=1)$, trauma $(\mathrm{n}=2)$ and unknown cause $(\mathrm{n}=6)$. Five-year survival from cardiac death was $98 \% \pm 1 \%$ for patients receiving RASIs versus $87 \% \pm 3 \%$ for patients not receiving RASIs (log-rank test, $\mathrm{P}<0.001$; see figure 1A). In addition, 5-year survival from all-cause death was $93 \% \pm 1 \%$ for patients receiving RASIs versus
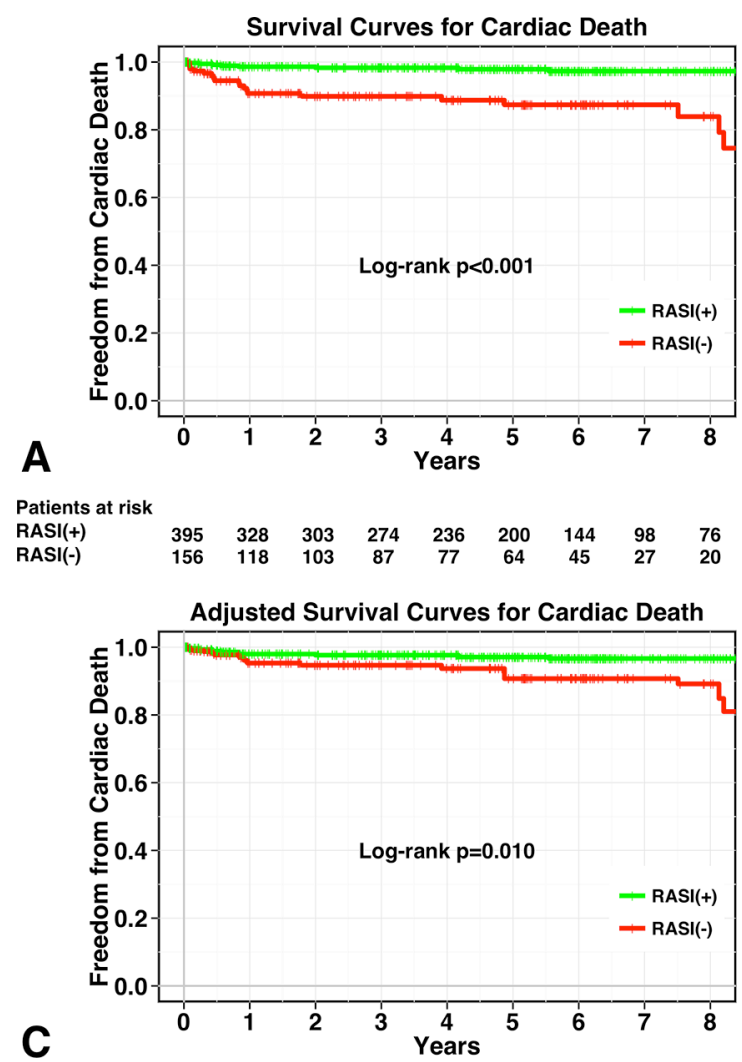

$76 \% \pm 4 \%$ for patients not receiving RASIs (log-rank test, $\mathrm{P}<0.001)$. After the adjustment with IPTW, survival analysis showed a significant association between RASI therapy and a lower risk of all-cause death and cardiac death (log-rank test, $\mathrm{P}=0.005$ for all-cause death and $\mathrm{P}=0.010$ for cardiac death; see figure 1C).

Similarly, during the follow-up periods, 47 episodes of HF occurred. Five-year survival from cardiac death and $\mathrm{HF}$ was $94 \% \pm 1 \%$ for patients receiving RASIs versus $81 \% \pm 3 \%$ for patients not receiving RASIs (log-rank test, $\mathrm{P}<0.001$; figure 1B). IPTW-adjusted event-free survival curves from cardiac death and HF showed a significant association between RASI therapy and a lower risk of cardiac death or HF (log-rank test, $\mathrm{P}=0.044$; figure 1D).

Univariate predictors of cardiac death and composite outcome are shown in table 3. In addition, clinical outcomes according to RASI therapy using Cox regression analysis are shown in table 4.

\section{Patient characteristics and echocardiographic results in non- IMR patients}

Of the 505 patients with no or trivial MR, $403(80 \%)$ patients received RASI before hospital discharge. Baseline characteristics and echocardiographic results of the patients with and without RASI therapy are shown in table 5 and table 6 , respectively. Patients without RASI therapy were less likely to have hypertension, anterior MI
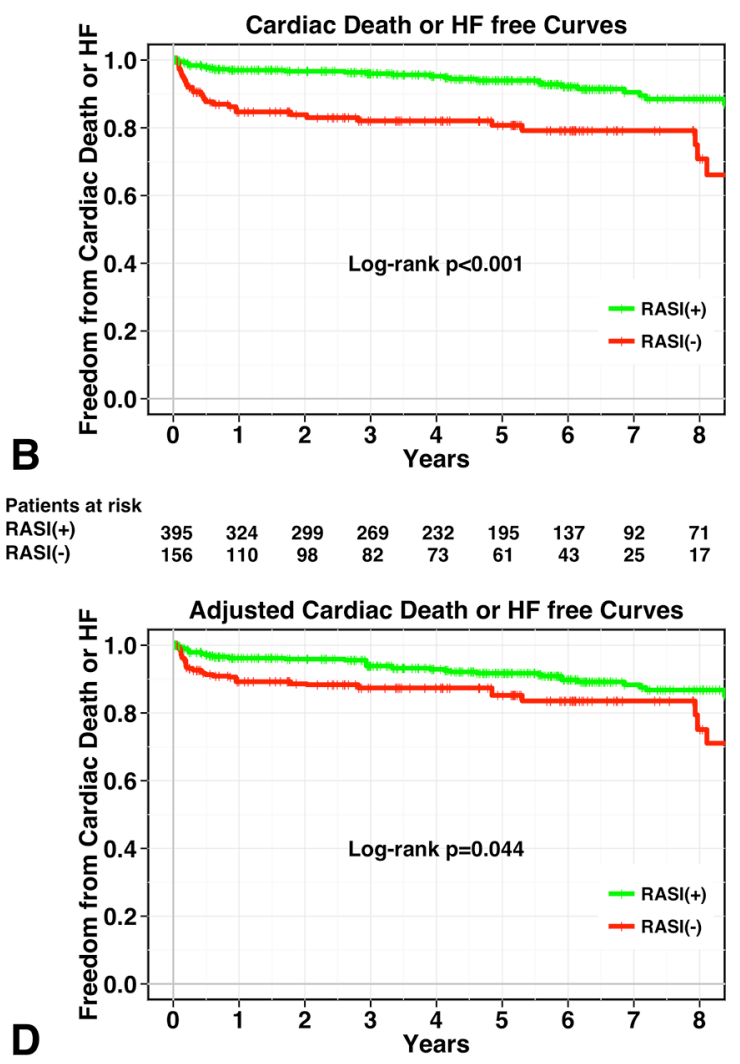

Figure 1 Kaplan-Meier curves for patient groups with RASI therapy (green line) and without RASI therapy (red line). Unadjusted curves for cardiac death $(\mathrm{A})$ and composite of cardiac death and HF (B) and inverse probability of treatmentweighted survival curves for cardiac death (C) and composite of cardiac death and HF (D). HF, heart failure; RASI, reninangiotensin system inhibitor. 
Table 3 Univariate predictors of cardiac death and composite outcome in patients with IMR

\begin{tabular}{|c|c|c|c|c|}
\hline & \multicolumn{2}{|l|}{ Cardiac death } & \multicolumn{2}{|c|}{ Cardiac death and heart failure } \\
\hline & HR $(95 \% \mathrm{Cl})$ & $P$ value & HR $(95 \% \mathrm{Cl})$ & $P$ value \\
\hline Age & 1.04 (1.01 to 1.07$)$ & 0.02 & 1.06 (1.04 to 1.09$)$ & $<0.001$ \\
\hline Male & 1.00 (0.44 to 2.29 ) & 0.99 & 1.47 (0.88 to 2.44$)$ & 0.14 \\
\hline Hypertension & 1.06 (0.55 to 2.02) & 0.87 & 1.62 (1.02 to 2.57 ) & 0.04 \\
\hline Dyslipidaemia & 0.97 (0.50 to 1.86$)$ & 0.92 & 1.01 (0.64 to 1.57 ) & 0.98 \\
\hline Diabetes mellitus & 1.52 (0.79 to 2.94$)$ & 0.21 & 1.69 (1.09 to 2.65$)$ & 0.02 \\
\hline Smoking & 1.22 (0.63 to 2.35 ) & 0.56 & 0.96 (0.61 to 1.53 ) & 0.87 \\
\hline Killip classification & 2.54 (1.95 to 3.30 ) & $<0.001$ & 2.16 (1.77 to 2.64$)$ & $<0.001$ \\
\hline Peak CK & 1.15 (1.08 to 1.23 ) & $<0.001$ & 1.11 (1.05 to 1.17 ) & $<0.001$ \\
\hline Creatinine & 1.30 (1.19 to 1.42 ) & $<0.001$ & 1.23 (1.14 to 1.34$)$ & $<0.001$ \\
\hline Prior Ml & 2.37 (1.04 to 5.42 ) & 0.04 & 1.92 (1.04 to 3.54 ) & 0.04 \\
\hline Anterior MI & 0.80 (0.42 to 1.54 ) & 0.51 & 1.23 (0.79 to 1.91$)$ & 0.36 \\
\hline $\mathrm{PCl}$ & 1.05 (0.37 to 2.96 ) & 0.93 & 0.70 (0.38 to 1.29$)$ & 0.25 \\
\hline Moderate or severe MR & 14.90 (7.74 to 28.68$)$ & $<0.001$ & 5.13 (3.19 to 8.25$)$ & $<0.001$ \\
\hline$\beta$-blocker & 0.38 (0.20 to 0.73 ) & 0.004 & 0.41 (0.26 to 0.64 ) & $<0.001$ \\
\hline Statins & 0.74 (0.39 to 1.43$)$ & 0.37 & 0.62 (0.39 to 0.96$)$ & 0.03 \\
\hline
\end{tabular}

Per 1000 IU/L increments.

$\mathrm{CK}$, creatine kinase; IMR, ischaemic mitral regurgitation; MI, myocardial infarction; PCI, percutaneous coronary intervention.

and $\beta$-blocker, and more likely to have smaller LV end-diastolic volume and end-systolic volume compared with patients with RASI therapy. Serum creatinine level and peak CK level were comparable between the two groups.

\section{Survival analysis in non-IMR patients}

During the follow-up periods, 34 deaths occurred in non-IMR patients. Of these, six were cardiac deaths (two $2 \mathrm{HFs}$, three 3 sudden deaths and one 1 ventricular arrhythmia). Details of the remaining 28 non-cardiac deaths were as follows: cancer $(\mathrm{n}=9)$, infectious disease $(n=7)$, stroke $(n=4)$, liver failure $(n=2)$, respiratory failure $(n=1)$, ruptured aortic aneurysm $(n=1)$, pancreatitis $(n=1)$, unknown cause $(n=3)$. Five-year survival from cardiac death was $99 \% \pm 1 \%$ for patients receiving RASIs versus $99 \% \pm 1 \%$ for patients not receiving RASIs (log-rank test, $\mathrm{P}=0.261$; see figure $2 \mathrm{~A})$. In addition, 5 -year survival from all-cause death was $95 \% \pm 1 \%$ for patients receiving RASIs versus $95 \% \pm 2 \%$ for patients not receiving RASIs (log-rank test, $\mathrm{P}=0.037$ ). After the adjustment with IPTW, survival analysis showed no significant association between RASI therapy and a lower risk of all-cause death and cardiac death (log-rank test, $\mathrm{P}=0.362$ for all-cause death and $\mathrm{P}=0.934$ for cardiac death; see figure $2 \mathrm{C}$ ).

Similarly, during the follow-up periods, 15 episodes of HF occurred. Five-year survival from cardiac death and HF was $97 \% \pm 1 \%$ for patients receiving RASIs versus $97 \% \pm 2 \%$ for patients not receiving RASIs. There were no significant

Table 4 Clinical outcome according to RASI therapy in patients with IMR

\begin{tabular}{|c|c|c|c|c|c|c|c|c|}
\hline & \multicolumn{2}{|c|}{ Treatment } & \multicolumn{2}{|l|}{ Univariate analysis } & \multicolumn{2}{|l|}{$\begin{array}{l}\text { Multivariate } \\
\text { analysis }\end{array}$} & \multicolumn{2}{|l|}{ IPTW } \\
\hline & $\begin{array}{l}\text { RASI(+) } \\
(n=395)\end{array}$ & $\begin{array}{l}\text { RASI(-) } \\
(n=156)\end{array}$ & $\begin{array}{l}\text { Unadjusted } \\
(95 \% \mathrm{Cl})\end{array}$ & $P$ value & $\begin{array}{l}\text { Adjusted HR } \\
(95 \% \mathrm{Cl})\end{array}$ & $P$ value & $\begin{array}{l}\text { Adjusted HR } \\
(95 \% \mathrm{Cl})\end{array}$ & $P$ value \\
\hline $\begin{array}{l}\text { All-cause } \\
\text { death }\end{array}$ & $34(9)$ & $39(25)$ & $0.27(0.17$ to 0.43$)$ & $<0.001$ & $0.44(0.27$ to 0.72$)$ & $0.001^{*}$ & $0.43(0.25$ to 0.74$)$ & 0.002 \\
\hline $\begin{array}{l}\text { Cardiac } \\
\text { death }\end{array}$ & $10(3)$ & $21(13)$ & $0.15(0.07$ to 0.32$)$ & $<0.001$ & $0.33(0.14$ to 0.76$)$ & $0.009^{*}$ & $0.28(0.12$ to 0.66$)$ & 0.004 \\
\hline $\begin{array}{l}\text { Composite } \\
\text { outcome }\end{array}$ & $29(7)$ & $31(20)$ & $0.30(0.18$ to 0.50$)$ & $<0.001$ & $0.53(0.30$ to 0.92$)$ & $0.025 \ddagger$ & $0.51(0.28$ to 0.95$)$ & 0.033 \\
\hline
\end{tabular}

${ }^{*}$ Covariates include peak CK, Killip classification, serum creatinine, prior MI, moderate/severe MR and $\beta$-blocker.

†Cardiac death or heart failure.

$\ddagger$ Adjusted with hypertension, peak CK, Killip classification, serum creatinine, prior MI, moderate/severe MR and $\beta$-blocker.

$\mathrm{CK}$, creatine kinase; IMR, ischaemic mitral regurgitation; IPTW, Inverse probability of treatment weighted; MI, myocardial infarction; RASI,

renin-angiotensin system inhibitor. 


\begin{tabular}{|c|c|c|c|c|}
\hline \multirow[t]{2}{*}{ Characteristics } & \multicolumn{3}{|c|}{ Unadjusted data } & \multirow{2}{*}{$\begin{array}{l}\text { IPTW } \\
\text { P value }\end{array}$} \\
\hline & $\begin{array}{l}\text { RASI (+) } \\
(n=403)\end{array}$ & $\begin{array}{l}\text { RASI (-) } \\
(n=102)\end{array}$ & $P$ value & \\
\hline Age, years, mean $\pm S D$ & $62 \pm 12$ & $65 \pm 12$ & 0.11 & 0.94 \\
\hline Gender, male/female & $334 / 69$ & $87 / 15$ & 0.55 & 0.26 \\
\hline \multicolumn{5}{|l|}{ Cardiovascular risk factors } \\
\hline Hypertension, $n(\%)$ & $230(57)$ & $46(45)$ & 0.03 & 0.83 \\
\hline Diabetes mellitus, $n(\%)$ & $131(33)$ & $26(25)$ & 0.17 & 0.48 \\
\hline Dyslipidaemia, n (\%) & $181(45)$ & $48(47)$ & 0.70 & 0.83 \\
\hline Current smoker, n (\%) & $173(43)$ & $36(35)$ & 0.16 & 0.34 \\
\hline Frailty & $8(2)$ & $5(5)$ & 0.10 & 0.80 \\
\hline $\mathrm{BMI}, \mathrm{kg} / \mathrm{m}^{2}, \operatorname{mean} \pm \mathrm{SD}$ & $24.5 \pm 3.6$ & $22.9 \pm 3.3$ & $<0.001$ & 0.16 \\
\hline ST segment elevation MI, $n(\%)$ & $316(78)$ & $76(75)$ & 0.40 & 0.99 \\
\hline Killip classification, n (\%) & $1.2 \pm 0.5$ & $1.2 \pm 0.6$ & 0.56 & 0.91 \\
\hline Prior Ml, n (\%) & $32(8)$ & $6(6)$ & 0.47 & 0.63 \\
\hline Primary PCl, n (\%) & $366(91)$ & $81(79)$ & 0.003 & 0.55 \\
\hline CABG, n (\%) & $7(2)$ & $14(14)$ & $<0.001$ & 0.93 \\
\hline Peak CK, IU/L & $2380 \pm 2641$ & $2194 \pm 2417$ & 0.52 & 0.96 \\
\hline Serum creatinine, mg/dL & $1.05 \pm 0.97$ & $1.07 \pm 0.39$ & 0.85 & 0.67 \\
\hline $\mathrm{eGFR}, \mathrm{mL} / \mathrm{min} / 1.73 \mathrm{~m}^{2}$ & $52 \pm 18$ & $49 \pm 21$ & 0.10 & 0.01 \\
\hline ACEI, $n(\%)$ & $296(73)$ & $0(0)$ & $<0.001$ & $<0.001$ \\
\hline ARB, $n(\%)$ & $107(27)$ & $0(0)$ & $<0.001$ & $<0.001$ \\
\hline$\beta$-blocker, n (\%) & $315(78)$ & $66(65)$ & 0.01 & 0.96 \\
\hline Statins, $n(\%)$ & $266(66)$ & $58(57)$ & 0.09 & 0.78 \\
\hline Initial TIMI grade flow 3, n(\%) & $81(20)$ & $21(21)$ & 0.91 & 0.68 \\
\hline Anterior MI, n (\%) & $216(54)$ & $40(39)$ & 0.01 & 0.69 \\
\hline
\end{tabular}

ACEl, angiotensin-converting enzyme inhibitor; ARB, angiotensin receptor blocker; BMI, body mass index; CABG, coronary artery bypass grafting; CK, creatine kinase; eGFR, estimated glomerular filtration rate; IMR, ischaemic mitral regurgitation; $\mathrm{MI}$, myocardial infarction; PCI, percutaneous coronary intervention; RASI, renin-angiotensin system inhibitor; TIMI, Thrombolysis In Myocardial Infarction.

Table 6 Baseline echocardiographic findings in non-IMR patients

\begin{tabular}{llll}
\hline & $\begin{array}{l}\text { RASI (+) } \\
(\mathbf{n = 4 0 3 )}\end{array}$ & $\begin{array}{l}\text { RASI (-) } \\
(\mathbf{n = 1 0 2 )}\end{array}$ & P value \\
\hline LV EDV, mL & $86 \pm 28$ & $75 \pm 24$ & 0.001 \\
\hline LV ESV, mL & $41 \pm 21$ & $35 \pm 18$ & 0.02 \\
\hline LVEF, \% & $55 \pm 10$ & $56 \pm 12$ & 0.41 \\
\hline LA dimension, cm & $3.5 \pm 0.6$ & $3.5 \pm 0.6$ & 0.98 \\
\hline $\begin{array}{l}\text { Moderate/severe MR, } \\
\text { n(\%) }\end{array}$ & $0(0)$ & $0(0)$ & - \\
\hline $\begin{array}{l}\text { Mitral deceleration } \\
\text { time, ms }\end{array}$ & $217 \pm 55$ & $213 \pm 56$ & 0.54 \\
\hline E/A ratio & $0.91 \pm 0.34$ & $0.95 \pm 0.35$ & 0.35 \\
\hline
\end{tabular}

EDV, end-diastolic volume; EF, ejection fraction; ESV, end-systolic volume; IMR, ischaemic mitral regurgitation; LA dimension, left atrial dimension; LV, left ventricular; MR, mitral regurgitation; RASI, renin-angiotensin system inhibitor. differences in the rate of the composite of cardiac death and HF between patients with and without RASI therapy (log-rank test, $\mathrm{P}=0.984$; figure 2B). In addition, IPTW-adjusted survival-free event-free survival curves from cardiac death and the composite of cardiac death and HF did not show significant associations between RASI therapy and these endpoints (log-rank test, $\mathrm{P}=0.170$; figure $2 \mathrm{D}$ )

\section{DISCUSSION}

The main findings of this study were as follows. (1) RASI therapy was associated with a lower incidence of adverse cardiac events in patients with IMR after AMI. (2) There were no significant differences in the incidence of cardiac events according to the use of RASI in patients without IMR.

It has been widely recognised that patients with IMR after AMI have poorer prognosis than those without IMR. IMR occurs as a consequence of global or regional LV 


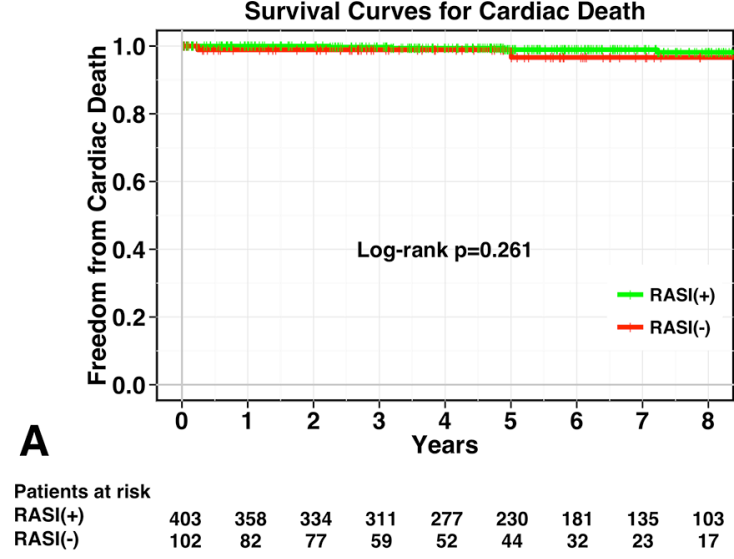

Adjusted Survival Curves for Cardiac Death

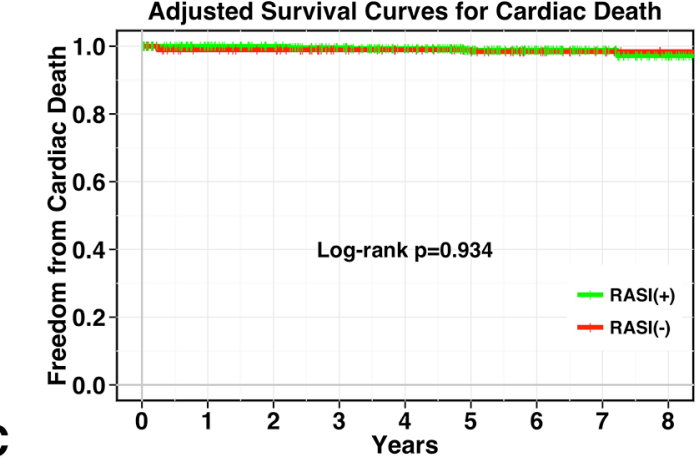

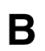

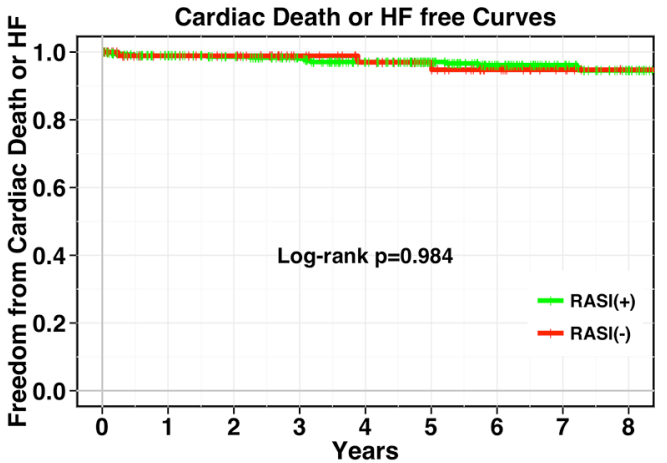

Patients at risk $\begin{array}{lccccccccc}\text { RASI(+) } & 403 & 355 & 331 & 307 & 271 & 228 & 177 & 133 & 101 \\ \text { RASI(-) } & 102 & 82 & 77 & 59 & 51 & 44 & 32 & 23 & 17\end{array}$

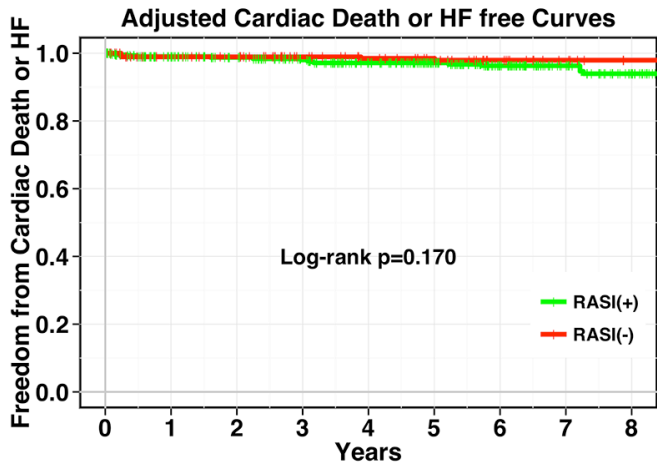

Figure 2 Kaplan-Meier curves for patient groups with RASI therapy (green line) and without RASI therapy (red line). Unadjusted curves for cardiac death (A) and composite of cardiac death and HF (B) and inverse probability of treatmentweighted survival curves for cardiac death (C) and composite of cardiac death and HF (D). HF, heart failure; RASI, reninangiotensin system inhibitor.

remodelling despite a structurally normal valve, which cause the leaflet tethering by displacement of papillary muscles. ${ }^{24-26}$ Accordingly, the therapeutic approaches should be aimed at the underlying LV dysfunction. Medical therapy including $\beta$-blockers and RASI for LV dysfunction and chronic HF is the essential therapy for patients with IMR. Cardiac resynchronisation therapy and coronary revascularisation are also considered in patients with an appropriate indication. Since mitral valve surgery can correct MR severity and improve symptoms of HF, surgical repair of IMR combined with coronary revascularisation has been thought to be a reasonable option. However, it is unclear whether it could improve longterm survival in patients with IMR who do not require $\mathrm{CABG}^{27}{ }^{28}$ Considering the uncertain survival benefit and operative risk in patients with IMR, medical therapy may currently be the only reasonable first-line strategy for the patients with IMR after AMI.

Previous studies reported that ACEI was efficacious in reducing IMR in patients with $\mathrm{HF}$ and $\mathrm{LV}$ dysfunction ${ }^{910}$; however, these studies did not assess the effect of ACEI on cardiovascular events. In a study that investigated the long-term prognosis of medically treated patients with functional MR and LV dysfunction receiving current standard pharmacological therapy, medical therapies including ACEI and $\beta$-blocker were not independent predictors of mortality. ${ }^{6}$ However, a more recent study demonstrated that the use of RASIs was associated with better long-term prognosis in patients with MI and significant (>moderate) IMR. ${ }^{29}$ Our present study is consistent with those results.

Although ACEIs (or ARB when an ACEI was not tolerated) are recommended in all patients after AMI, a considerable portion of patients after AMI do not receive RASIs in the real-world clinical practice mainly because of intolerance to RASI therapy such as hypotension, renal insufficiency and hyperkalemia. The prescription rate of RASIs at discharge after AMI was approximately $60 \%$ in 1998 and $80 \%$ in 2010 in a post-MI registry in Japan. ${ }^{30}$ According to a Japanese registry study that included patients who underwent PCI or CABG, about $70 \%$ of patients with history of MI received RASI therapy at discharge, which means almost $30 \%$ of patients did not receive RASI therapy. ${ }^{31}$ Our results suggest that introduction at a low dose and uptitration of RASI should always be considered even in patients with IMR who seem to be intolerant to RASI therapy.

This study did not find a significant association between RASI therapy and reduced cardiac events in patients who did not have IMR after AMI. A possible explanation for these results may be the different patient characteristics in this study compared with previous studies. Many of the non-IMR patients who did not receive RASI therapy had non-dilated LV with preserved EF; in addition, most of 
the patients in this study were revascularised by primary PCI or emergent CABG during acute phase of MI. In the PREAMI study, ${ }^{19}$ which investigated whether ACEIs show beneficial effects in elderly postinfarction patients with preserved LVEF, ACEI therapy was associated with reduced LV remodelling, but not with better clinical outcomes. Because non-IMR patients in this study seemed to have a lower risk of cardiovascular events compared with patients in previous trials of ACEIs who had reduced LVEF or chronic HF, this might lead to a failure to find the benefit of RASI therapy in cardiovascular prevention in this patient population. Our results suggest that patients with IMR might receive clinical benefit from RASI therapy after AMI regardless of MR severity and LV dysfunction in the reperfusion setting.

Our study has several limitations. First, since our study was based on a retrospective analysis, initiation of ACEI therapy depended on the physician's discretion. Although we performed adjustment with the inverse probability treatment weighting to minimise the selection bias, unmeasured confounding factors might be present. Second, we evaluated the long-term effect of RASI based on the medications at discharge. However, the dose and class of RASI, and discontinuation after discharge were not assessed. Thus, patients with and without RASI therapy were compared in an intention-to-treat fashion based on the initial treatment assignment. Duration of RASI therapy may have a significant impact on clinical outcomes in patients with IMR. Third, the peak CK levels may be less accurate than sigma CK levels to evaluate the infarct size. However, since there were wide varieties in the timing and frequency of the assessments of CK levels, we could not calculate the sigma CK levels in all patients. Finally, we assessed IMR semiquantitatively and did not evaluate it quantitatively. The use of colour Doppler for determining MR severity might not be very accurate because of technical and haemodynamic limitations, ${ }^{32}$ but is part of the routine echocardiographic examination. In addition, although we defined IMR with rigorous echocardiographic criteria, we could not completely exclude patients with pre-existing MR.

Contributors KK: acquisition of data, analysis and interpretation of data, drafting of manuscript; SK: study concept and design, analysis and interpretation of data; MK, RM, YS, TK, TY, NE, AK, MK: acquisition of data; YF: critical revision.

Competing interests None declared.

Ethics approval Institutional Review Board of Kobe City Medical Center General Hospital.

Provenance and peer review Not commissioned; externally peer reviewed.

Data sharing statement There are no additional data available for this paper.

Open Access This is an Open Access article distributed in accordance with the Creative Commons Attribution Non Commercial (CC BY-NC 4.0) license, which permits others to distribute, remix, adapt, build upon this work non-commercially, and license their derivative works on different terms, provided the original work is properly cited and the use is non-commercial. See: http://creativecommons.org/ licenses/by-nc/4.0/

(c) Article author(s) (or their employer(s) unless otherwise stated in the text of the article) 2017. All rights reserved. No commercial use is permitted unless otherwise expressly granted.

\section{REFERENCES}

1. Bursi F, Enriquez-Sarano M, Nkomo VT, et al. Heart failure and death after myocardial infarction in the community: the emerging role of mitral regurgitation. Circulation 2005;111:295-301.

2. Pellizzon GG, Grines CL, Cox DA, et al. Importance of mitral regurgitation inpatients undergoing percutaneous coronary intervention for acute myocardial infarction: the Controlled Abciximab and Device Investigation to Lower Late Angioplasty Complications (CADILLAC) trial. J Am Coll Cardiol 2004;43:1368-74.

3. Grigioni F, Enriquez-Sarano M, Zehr KJ, et al. Ischemic mitral regurgitation: long-term outcome and prognostic implications with quantitative Doppler assessment. Circulation 2001;103:1759-64.

4. Aronson D, Goldsher N, Zukermann R, et al. Ischemic mitral regurgitation and risk of heart failure after myocardial infarction. Arch Intern Med 2006;166:2362-8.

5. Amigoni M, Meris A, Thune JJ, et al. Mitral regurgitation in myocardial infarction complicated by heart failure, left ventricular dysfunction, or both: prognostic significance and relation to ventricular size and function. Eur Heart J 2007;28:326-33.

6. Agricola E, lelasi A, Oppizzi M, et al. Long-term prognosis of medically treated patients with functional mitral regurgitation and left ventricular dysfunction. Eur J Heart Fail 2009;11:581-7.

7. Weiland DS, Konstam MA, Salem DN, et al. Contribution of reduced mitral regurgitant volume to vasodilator effect in severe left ventricular failure secondary to coronary artery disease or idiopathic dilated cardiomyopathy. Am J Cardiol 1986;58:1046-50.

8. Hamilton MA, Stevenson LW, Child JS, et al. Sustained reduction in valvular regurgitation and atrial volumes with tailored vasodilator therapy in advanced congestive heart failure secondary to dilated (ischemic or idiopathic) cardiomyopathy. Am J Cardiol 1991;67:259-63.

9. Seneviratne B, Moore GA, West PD. Effect of captopril on functional mitral regurgitation in dilated heart failure: a randomised double blind placebo controlled trial. Br Heart J 1994;72:63-8.

10. Levine AB, Muller C, Levine TB. Effects of high-dose lisinoprilisosorbide dinitrate on severe mitral regurgitation and heart failure remodeling. Am J Cardiol 1998;82:1299-301.

11. Shimoyama H, Sabbah HN, Rosman $\mathrm{H}$, et al. Effects of long-term therapy with enalapril on severity of functional mitral regurgitation in dogs with moderate heart failure. J Am Coll Cardiol 1995;25:768-72.

12. Pfeffer MA, Braunwald E, Moyé LA, et al. Effect of captopril on mortality and morbidity in patients with left ventricular dysfunction after myocardial infarction. Results of the survival and ventricular enlargement trial. The SAVE Investigators. N Engl J Med 1992;327:669-77.

13. Effect of ramipril on mortality and morbidity of survivors of acute myocardial infarction with clinical evidence of heart failure. The Acute Infarction Ramipril Efficacy (AIRE) Study Investigators. Lancet 1993;342:821-8.

14. Køber L, Torp-Pedersen C, Carlsen JE, et al. A clinical trial of the angiotensin-converting-enzyme inhibitor trandolapril in patients with left ventricular dysfunction after myocardial infarction. Trandolapril Cardiac Evaluation (TRACE) Study Group. N Engl J Med 1995;333:1670-6.

15. Dickstein K, Kjekshus J. OPTIMAAL Steering Committee of the OPTIMAAL Study Group. Effects of losartan and captopril on mortality and morbidity in high-risk patients after acute myocardial infarction: the OPTIMAAL randomised trial. Optimal trial in myocardial infarction with angiotensin II antagonist losartan. Lancet 2002;360:752-60.

16. Pfeffer MA, McMurray JJ, Velazquez EJ, et al. Valsartan, captopril, or both in myocardial infarction complicated by heart failure, left ventricular dysfunction, or both. N Engl J Med 2003;349:1893-906.

17. Pfeffer MA, Swedberg K, Granger CB, et al. Effects of candesartan on mortality and morbidity in patients with chronic heart failure: the charm-overall programme. Lancet 2003;362:759-66.

18. Nishimura RA, Otto CM, Bonow RO, et al. AHA/ACC guideline for the management of patients with valvular heart disease: a report of the American college of cardiology/American heart association task force on practice guidelines. J Am Coll Cardiol 2014;2014:e57-185.

19. Ferrari R. Perindopril and Remodeling in Elderly with Acute Myocardial Infarction Investigators. Effects of angiotensin-converting enzyme inhibition with perindopril on left ventricular remodeling and clinical outcome: results of the randomized perindopril and remodeling in elderly with acute myocardial infarction (PREAMI) Study. Arch Intern Med 2006;166:659-66.

20. Braunwald E, Domanski MJ, Fowler SE, et al. PEACE Trial Investigators. Angiotensin-converting-enzyme inhibition in stable coronary artery disease. N Engl J Med 2004;351:2058-68. 
21. Corti MC, Guralnik JM, Salive ME, et al. Serum albumin level and physical disability as predictors of mortality in older persons. JAMA 1994;272:1036-42.

22. Bandeen-Roche K, Xue QL, Ferrucci L, et al. Phenotype of frailty: characterization in the women's health and aging studies. $J$ Geronto A Biol Sci Med Sci 2006;61:262-6.

23. Matsuo S, Imai E, Horio M, et al. Revised equations for estimated GFR from serum creatinine in Japan. Am J Kidney Dis 2009;53:982-92.

24. Otsuji Y, Handschumacher MD, Schwammenthal E, et al. Insights from three-dimensional echocardiography into the mechanism of functional mitral regurgitation: direct in vivo demonstration of altered leaflet tethering geometry. Circulation 1997;96:1999-2008.

25. Otsuji Y, Handschumacher MD, Liel-Cohen N, et al. Mechanism of ischemic mitral regurgitation with segmental left ventricular dysfunction: three-dimensional echocardiographic studies in models of acute and chronic progressive regurgitation. J Am Coll Cardio 2001;37:641-8.

26. Kumanohoso T, Otsuji Y, Yoshifuku S, et al. Mechanism of higher incidence of ischemic mitral regurgitation in patients with inferior myocardial infarction: quantitative analysis of left ventricular and mitral valve geometry in 103 patients with prior myocardial infarction. J Thorac Cardiovasc Surg 2003;125:135-43.
27. Wu AH, Aaronson KD, Bolling SF, et al. Impact of mitral valve annuloplasty on mortality risk in patients with mitral regurgitation and left ventricular systolic dysfunction. J Am Coll Cardiol 2005;45:381-7

28. Mihaljevic T, Lam BK, Rajeswaran J, et al. Impact of mitral valve annuloplasty combined with revascularization in patients with functional ischemic mitral regurgitation. J Am Coll Cardiol 2007;49:2191-201

29. Okura H, Kataoka T, Yoshida K. Renin-angiotensin system inhibitors in patients with myocardial infarction and secondary mitral regurgitation. Heart 2016;102:694-700.

30. Hara M, Sakata Y, Nakatani D, et al. Comparison of 5-year survival after acute myocardial infarction using angiotensin-converting enzyme inhibitor versus angiotensin II receptor blocker. Am J Cardiol 2014;114:1-8.

31. Nishino T, Furukawa Y, Kaji S, et al. Distinct survival benefits of angiotensin-converting enzyme inhibitors/angiotensin II receptor blockers in revascularized coronary artery disease patients according to history of myocardial infarction. Circ J 2013;77:1242-52.

32. Zoghbi WA, Enriquez-Sarano M, Foster E, et al. Recommendations for evaluation of the severity of native valvular regurgitation with twodimensional and Doppler echocardiography. J Am Soc Echocardiogr 2003;16:777-802. 